\title{
DESEMPENHO E INTER-RELAÇÕES DO SETOR DE FERTILIZANTES: UMA ANÁLISE SEGUNDO A ÓTICA DE INSUMO-PRODUTO' ${ }^{1}$
}

\author{
Nicole Rennó Castro² \\ Adriana Ferreira Silva ${ }^{3}$ \\ Leandro Gilio ${ }^{4}$
}

\begin{abstract}
0 crescimento na demanda mundial por alimentos e biocombustíveis tem pressionado o setor agropecuário em termos de elevação de produção e produtividade. Nesse contexto, o setor de fertilizantes se torna altamente estratégico, dado que o crescimento da produção agrícola tem associação direta à utilização desse insumo. No Brasil, a elevada demanda por fertilizantes tem sido atendida, essencialmente, por meio de importações, o que gera desafios a um maior dinamismo do setor agropecuário. Posto isso, este estudo analisa o desempenho do setor de fertilizantes e suas inter-relações com os demais setores da economia brasileira, segundo a ótica do modelo insumoproduto. Os resultados demonstraram a importância do setor em termos de suas inter-relações com os demais setores da economia brasileira. Desse modo, ações dos agentes públicos e privados no sentido de reduzir a dependência do setor em relação ao mercado externo podem contribuir para o crescimento da economia nacional, em especial do setor agrícola.
\end{abstract}

Palavras-chave: fertilizantes; inter-relações; matrizes insumo-produto.

\section{PERFORMANCE AND INTERRELATIONSHIPS OF THE FERTILIZER SECTOR: AN ANALYSIS BASED ON THE INPUT-OUTPUT MODELS}

The growing of world demand for food and biofuels has put pressure on the agricultural sector in terms of increased production and productivity. In this context, the fertilizer sector becomes highly strategic, with crop volume growth strongly associated with its use. In Brazil, there is a strong dependence on the import of fertilizers, which ends up generating obstacles to a greater dynamism of the agribusiness sector, even with the country's great emphasis on world agricultural production and high internal demand for this agricultural input. Therefore, this study aims to analyze the behavior of the fertilizer sector and its interrelations with the other sectors of the Brazilian economy, according to the input-output model. The results highlight the importance of the sector in terms of its interrelations with the other sectors of the Brazilian economy, which allows to conclude that investments in this sector, by reducing its dependence on the external market, can contribute significantly to the growth Brazilian economy, especially for the agricultural sector.

Keywords: fertilizers; interrelationships; input-output models.

1. DOI: http://dx.doi.org/10.38116/ppp56art6

2. Professora adjunta na Universidade Federal de São João Del Rei (UFSJ) e pesquisadora no Centro de Estudos Avançados em Economia Aplicada (Cepea) da Escola Superior de Agricultura "Luiz de Queiroz" (Esalq) na Universidade de São Paulo (USP).

3. Professora adjunta na Universidade Federal de Goiás (UFG).E-mail: <adsilva@ufg.br>.

4. Pesquisador do Centro de Agronegócio Global do Insper (Insper). E-mail: <leandrog3@insper.edu.br>. 


\section{RENDIMIENTO E INTER-RELACIONES DEL SECTOR FERTILIZANTE: UN ANÁLISIS SEGÚN EL PUNTO DE PRODUCCIÓN}

El crecimiento de la demanda mundial de alimentos y biocombustibles ha ejercido presión para incrementar la producción y la productividad agrícola. En este contexto, el sector de los fertilizantes se vuelve estratégico, mientras el crecimiento de la producción agrícola está directamente asociado con el uso de este insumo. En Brasil, la gran demanda de fertilizantes se ha cubierto principalmente mediante importaciones, lo que implica desafíos para un mayor dinamismo en el sector agrícola. Este estudio analiza el desempeño del sector de fertilizantes y sus interrelaciones con otros sectores de la economía brasileña, utilizando un modelo insumo-producto (MIP). Los resultados muestran la importancia del sector en términos de sus interrelaciones con otros sectores de la economía brasileña. Así, las acciones de los agentes públicos y privados para reducir la dependencia externa del sector pueden contribuir con el desarrollo de la economía brasileña, especialmente en el sector agrícola.

Palabras clave: fertilizantes; interrelaciones; matrices de insumo-producto.

\section{PERFORMANCE ET RELATIONS DU SECTEUR DES ENGRAIS: UNE ANALYSE SELON LA PERSPECTIVE DU MODĖLE DES INTRANTS-PRODUITS}

La croissance de la demande mondiale de produits alimentaires et de biocarburants a exercé des pressions sur le secteur agricole en termes d'augmentation de la production et de la productivité. Dans ce contexte, le secteur des engrais devient hautement stratégique, étant donné que la croissance de la production agricole est directement associée à l'utilisation de cet intrant. Au Brésil, la forte demande d'engrais a été satisfaite, essentiellement, par les importations, ce qui crée des défis pour un plus grand dynamisme dans le secteur agricole. Cela dit, cette étude analyse la performance du secteur des engrais et ses relations avec les autres secteurs de l'économie brésilienne, selon la perspective du modèle des intrants-produits. Les résultats ont démontré l'importance du secteur en termes de ses relations avec d'autres secteurs de l'économie brésilienne. Ainsi, les actions des agents publics et privés pour réduire la dépendance du secteur à l'égard du marché étranger peuvent contribuer à la croissance de l'économie nationale, notamment dans le secteur agricole.

Mots-clés: engrais; interrelations; matrices d'entrée-produit.

JEL: 044; Q32; Q34; Q56.

\section{INTRODUÇÃO}

$\mathrm{O}$ aumento da população e da renda mundial, em paralelo ao uso intensivo de biocombustíveis, tem elevado a demanda por produtos agropecuários. Nesse cenário, maiores investimentos em tecnificação e utilização eficiente de corretivos e fertilizantes, que favoreçam o aumento na produtividade das lavouras de forma sustentável, têm se tornado tema central no debate sobre o futuro da agricultura (Bradsher e Martin, 2008).

Segundo estudo de FAO (2004), cada tonelada de fertilizante mineral aplicada em um hectare, em média, equivale à produção de quatro novos hectares sem adubação (de acordo com princípios técnicos que permitam sua máxima eficiência). 
Desse modo, constata-se a estreita relação entre o aumento no uso desse insumo e a elevação na produtividade agrícola, o que leva à otimização do uso da terra.

Lopes e Guilherme (2007) destacam que o uso de fertilizantes e corretivos para o melhoramento da fertilidade do solo transcende o efeito de aumento na produtividade. Tal prática agrega benefícios relacionados à capacidade de reduzir a degradação química, física e biológica do solo, conservando a qualidade da água e a saúde das plantas e contribuindo para reduzir o desmatamento, a erosão e a emissão de gases do efeito estufa (Lopes e Guilherme, 2007).

Em escala global, o consumo de fertilizantes registrou aumento médio de 50\% entre os anos de 1994 e 2014, impulsionado pela expansão em 113\% na demanda de países em desenvolvimento, segundo IFA (2016). No Brasil, a demanda por fertilizantes também tem sido crescente. Entre os anos safra de 1992/1993 e 2016/2017, o consumo nacional registrou alta de $255 \%$ (Anda, 2018). Entre outros fatores, essa elevação se refletiu diretamente sobre a produtividade agrícola no período: entre os anos safra de 1992/1993 e 2016/2017, a área plantada com grãos aumentou 64\% no Brasil, e produção registrou crescimento de $173 \%$ (Conab, 2016).

Para o agronegócio brasileiro, bem como para a economia do país como um todo, a crescente demanda mundial por produtos de base agropecuária representa uma oportunidade. $\mathrm{O}$ agronegócio historicamente exerce papel importante e estratégico na economia brasileira, representando em 2016 cerca de $20 \%$ do Produto Interno Bruto (PIB) do país (Cepea, 2017). O setor também atua como importante gerador de divisas, amenizando o resultado deficitário verificado em outras atividades econômicas brasileiras no comércio internacional. De acordo com informaçóes do Ministério da Agricultura, Pecuária e Abastecimento - Mapa (Brasil, 2017), em 2016, as exportaçôes do agronegócio representaram 46\% das exportaçóes nacionais, com a balança comercial do setor registrando superavit de quase US\$ 71 bilhóes. Para o total do Brasil, considerando todos os setores de atividade, o superavit foi de US $\$ 48$ bilhôes. Tal desempenho reflete-se na posição de destaque que o agronegócio brasileiro exerce no contexto do comércio internacional de produtos agropecuários. Em 2016, o Brasil terminou o ano com uma fatia de 5,7\% do mercado global, abaixo apenas dos Estados Unidos, com 11\%, e Europa, com 41\% (FAO, 2018).

Como efeito, o Brasil também está entre os maiores demandantes globais de fertilizantes. De acordo com dados de IFA (2016), em 2014 o Brasil demandou 14 milhóes de toneladas de fertilizantes, o que lhe conferiu o quarto lugar mundial no consumo do produto, atrás apenas da China, da Índia e dos Estados Unidos. Por outro lado, pela ótica da produção, o Brasil detém baixa colocação no ranking mundial: em 2014, 92\% do potássio consumido no país derivou de importaçôes; para o nitrogênio, o percentual foi de 73\%, e para o fósforo, de 46\% (IFA, 2016). 
A baixa participação da produção interna sobre o consumo total explicita a dependência da agricultura brasileira com relação às importaçóes desse insumo, verificando-se a dificuldade da indústria de insumos nacional em acompanhar o elevado ritmo de crescimento da demanda interna pelo produto (Saab e Paula, 2008). Segundo dados de Anda (2018), entre 2007 e 2017 as entregas de fertilizantes no Brasil aumentaram 39,8\%, passando de 24,61 milhóes para 34,4 milhóes de toneladas; por sua vez, a produção interna do insumo diminuiu $16,3 \%$, reduzindo de 9,8 milhóes de toneladas, em 2007, para 8,2 milhóes, em 2017.

Como destacado por Nogueira (2008), a dependência das importações de fertilizantes pelo Brasil tem provocado um debate sobre políticas públicas e estratégias privadas para aprimorar o funcionamento desse mercado no país. Saab e Paula (2008) avaliam que os fertilizantes estão entre os insumos que mais podem afetar os custos de produção agrícola e, por essa razão, caracterizam-se como fatores críticos para a competitividade das commodities brasileiras no mercado internacional.

Desse modo, choques ocorridos no setor de fertilizantes (decorrentes de variaçóes cambiais e de preços internos ou externos, de políticas públicas setoriais, entre outros) podem provocar efeitos multiplicadores importantes sobre o agronegócio e a economia brasileira - efeitos que ainda são pouco estudados pela literatura científica. Nesse sentido, este artigo tem como objetivo analisar o desempenho do setor de fertilizantes e suas inter-relaçóes com os demais setores da economia brasileira segundo a ótica do modelo insumo-produto, fazendo-se uso da matriz brasileira do ano de 2008. Busca-se fornecer informaçóes a respeito da relevância do setor de fertilizantes no sistema econômico brasileiro e de possíveis impactos sobre os demais setores produtivos diante de transformaçóes que incidam sobre esta atividade.

$\mathrm{O}$ modelo de insumo-produto tem sido amplamente utilizado na literatura científica em análises setoriais que visam avaliar a importância de setores e suas inter-relaçôes. Entre os estudos no Brasil, pode-se destacar Guilhoto et al. (1994), que avaliou setores-chave da economia brasileira e índices de ligação intersetorial, e trabalhos como o de Amorim, Coronel e Teixeira (2009), Figueiredo, Barros e Guilhoto (2005) e Souza et al. (2012), que desenvolveram análises setoriais voltadas à produção agropecuária. Apesar da existência de diversos trabalhos que avaliam setores relacionados ao agronegócio utilizando o modelo insumo-produto, ainda se verifica a inexistência de análises recentes que lancem foco sobre o setor de fertilizantes e suas inter-relaçóes. Acredita-se, portanto, que os resultados desse estudo venham a contribuir e fornecer subsídios para se ampliar a discussão na área econômica acerca desse tema. 


\section{PANORAMA GERAL DO MERCADO BRASILEIRO DE FERTILIZANTES}

O gráfico 1 apresenta a evolução da área plantada e da produção de grãos, assim como do consumo brasileiro de fertilizantes, entre os anos safra 1992/1993 e 2015/2016. No período, a área plantada brasileira aumentou 64\%. Paralelamente, a produção de grãos registrou crescimento de $173 \%$. Essa significativa expansão se deve ao aumento na produtividade da agricultura nacional, o que - entre outros fatores - reflete o uso crescente de fertilizantes (Gasques, Bacchi e Bastos, 2018). Entre os anos safra de 1992/1993 e 2016/2017, o consumo de fertilizantes cresceu 255\%. Gasques, Bacchi e Bastos (2018) destacam que o aumento das vendas de máquinas agrícolas, juntamente com a melhora na sua qualidade, e o uso de defensivos agropecuários também foram determinantes para o aumento na produtividade da agricultura brasileira.

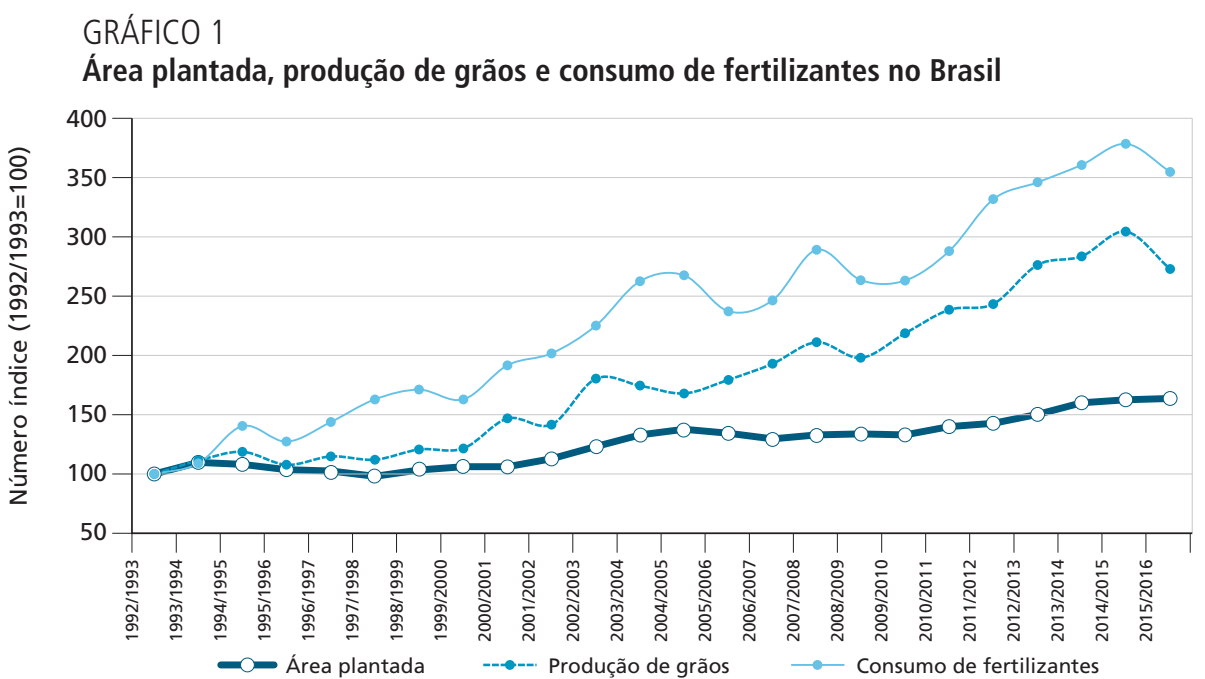

Fontes: Conab (2016) e Anda (2018).

Especificamente na safra 2015/2016, pôde-se constatar um recuo de 6\% no uso de fertilizantes (gráfico 1). Nesse período, o atraso na liberação do crédito agrícola e a desvalorização do câmbio refletiram-se em queda nos investimentos do produtor rural, entre eles a compra de adubos e fertilizantes. Esse cenário, associado às adversidades climáticas que permearam o setor, com estiagens prolongadas, altas temperaturas e excessos de chuvas, impactaram a produtividade e a produção agrícola, que recuou 10\% na safra 2015/2016 (Conab, 2016).

A tabela 1 apresenta dados dos quatro maiores consumidores mundiais de fertilizantes. Em 2014, o Brasil demandou 14 milhões de toneladas de fertilizantes, o que lhe conferiu o quarto lugar mundial no consumo do produto, atrás apenas da China (51,7 milhões), da Índia (25,3 milhōes) e dos Estados Unidos (20,3 milhōes). Como se verifica na tabela 1, entre os anos de 1990 e 2014, 
o consumo brasileiro de fertilizantes teve um crescimento médio anual de $6,1 \%$. E no acumulado do período, a demanda brasileira por fertilizantes cresceu $337 \%$, percentual expressivamente superior ao dos três primeiros maiores consumidores.

TABELA 1

Consumo de fertilizantes por países, em milhões de toneladas de nutrientes e variação média anual e total

\begin{tabular}{|c|c|c|c|c|c|c|}
\hline & 1990 & 2000 & 2010 & 2014 & \multirow{2}{*}{$\begin{array}{c}\text { Taxa média } \\
\text { anual (\%) }\end{array}$} & \multirow{2}{*}{$\begin{array}{c}\text { Variação tota } \\
(\%)\end{array}$} \\
\hline & \multicolumn{4}{|c|}{ Milhões de toneladas de nutrientes } & & \\
\hline China & 26,8 & 34,7 & 49,5 & 51,7 & 2,7 & 93 \\
\hline Índia & 12,0 & 18,8 & 28,1 & 25,3 & 3,0 & 111 \\
\hline EUA & 18,6 & 16,7 & 19,8 & 20,3 & 0,4 & 9 \\
\hline Brasil & 3,2 & 7,3 & 10,1 & 14,0 & 6,1 & 337 \\
\hline Mundo & 137,0 & 129,4 & 136,7 & 168,7 & 0,8 & 23 \\
\hline
\end{tabular}

Fonte: IFA (2016).

O crescimento no consumo de fertilizantes - em paralelo aos choques que marcaram o mercado de commodities nos últimos anos - tem resultado em significativas altas nos preços do insumo (gráfico 2). De forma geral, a maior alta anual ocorreu em 2008, como se observa no gráfico 2. No Brasil, a alta real anual em 2008 (em relaçáo a 2007) foi de, aproximadamente, $63 \%$ e, no mercado internacional, a variação foi superior a 137\%. No acumulado entre 1995 e 2015, a variação de preços foi de $201,9 \%$ no mercado externo e de $143,7 \%$ no mercado brasileiro.

\section{GRÁFICO 2}

Comportamento dos preços reais dos fertilizantes e da taxa de câmbio ${ }^{1}$ (1995-2015)

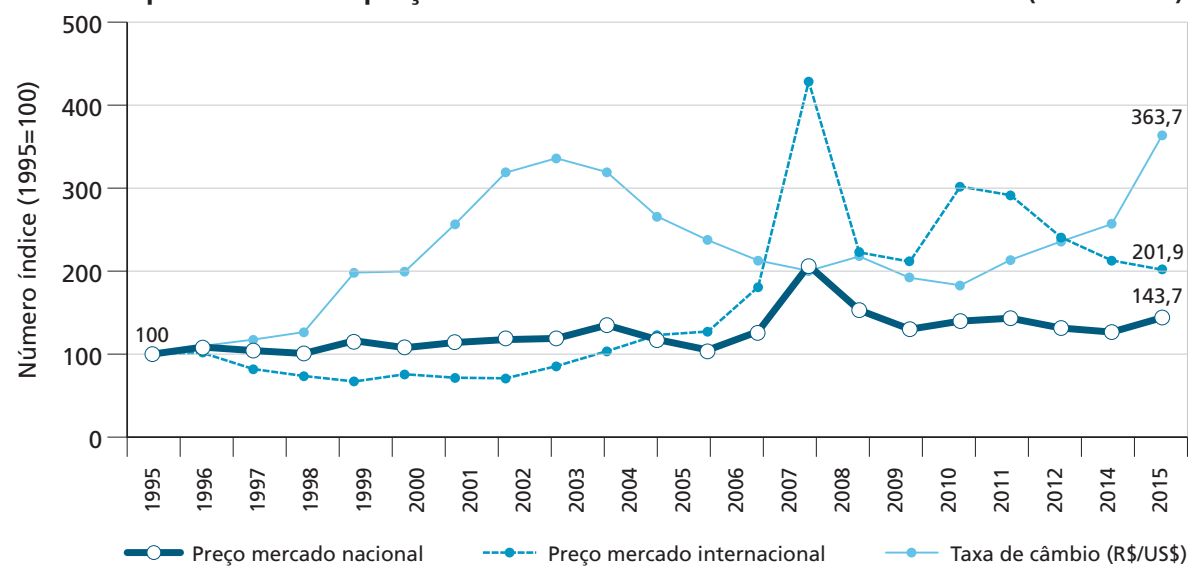

Fontes: FGV (2017) e IFA (2016).

Nota: ${ }^{1}$ Para o mercado doméstico, a evolução real de preços se refere ao IPA-Fertilizantes descontado o efeito da inflação pelo IGP-DI. Para o mercado internacional, foi empregado o Índice de Preços Real (IPR), calculado pelo Banco Mundial. 
Os dados do gráfico 2 mostram que, a partir de 2005, as variações de preço dos fertilizantes no mercado internacional mantiveram-se acima das registradas no mercado doméstico. O comportamento do câmbio, com o real relativamente mais valorizado diante do dólar, principalmente entre 2005 e 2011, amenizou as transmissóes das altas internacionais para o mercado brasileiro. Por outro lado, de 2012 em diante, as cotaçóes internacionais reduziram. No entanto, com o câmbio em processo de desvalorização (R $\$ / U S \$)$, tais quedas também não foram transmitidas em mesma magnitude ao mercado doméstico e os preços internos do produto mantiveram certa estabilidade no período.

Especificamente em relação ao choque de preços de 2008, as altas cotaçôes das commodities agrícolas, um reflexo da aquecida demanda por alimentos e biocombustíveis, estimularam a expansão do plantio, dando relevante impulso aos preços dos fertilizantes (o que pode ser observado no gráfico 2). Segundo Bradsher e Martin (2008), as fábricas e as minas de fertilizantes do mundo náo conseguiram acompanhar o ritmo de crescimento da demanda por adubos. Com a oferta limitada, e a demanda acompanhando a alta de preços das commodities, houve incremento expressivo nos preços dos fertilizantes.

No final desse mesmo ano, a crise financeira global resultou em desaquecimento da demanda por alimentos, levando agricultores a reavaliarem investimentos e o uso de fertilizantes, reduzindo o consumo no plantio da safra seguinte. A partir de entáo, o mercado de fertilizantes passou por um movimento de ajuste de oferta e demanda, com preços oscilando conforme o comportamento do ambiente macroeconômico internacional (Seae, 2011).

A figura 1 apresenta, esquematicamente, a cadeia produtiva do insumo, cujo complexo produtor envolve atividades que vão desde a extração da matéria-prima até as formulaçôes aplicadas diretamente na agricultura. 
FIGURA 1

Cadeia produtiva de fertilizantes de forma esquemática

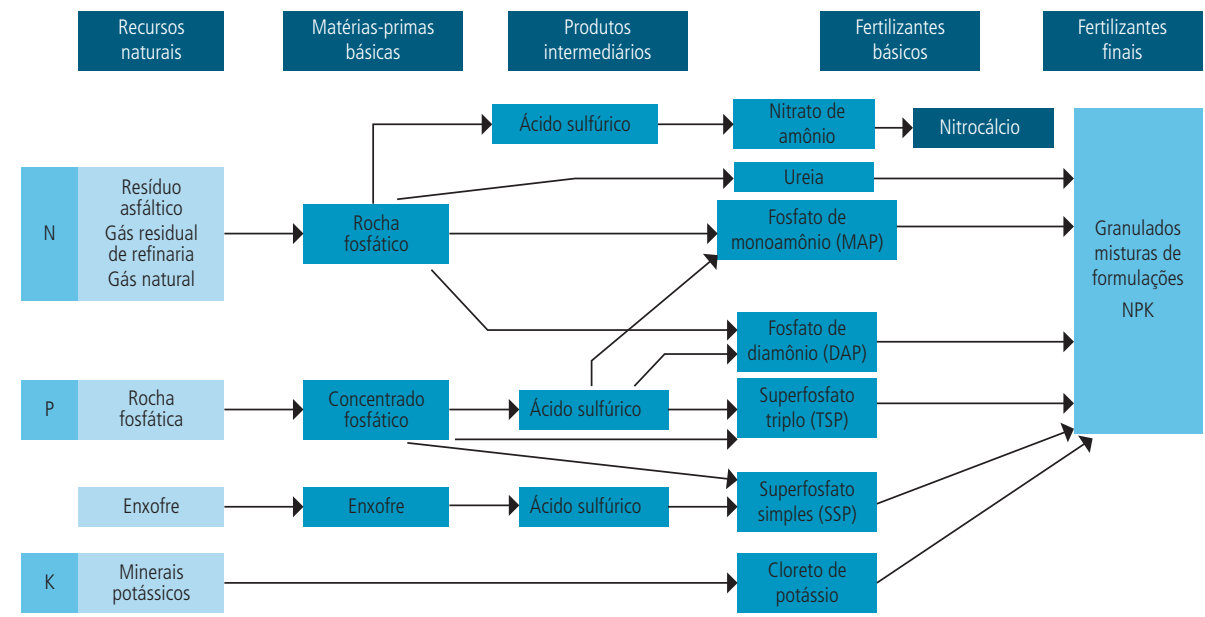

Fonte: Costa e Silva (2012).

Devido à sua importância no processo produtivo, os principais elementos químicos utilizados na elaboração dos fertilizantes são o nitrogênio $(\mathrm{N})$, o fósforo (P) e o potássio (K). Os demais macros e micronutrientes têm importância biológica menos expressiva, sendo utilizados em quantidades menores e não tendo, portanto, expressáo econômica na indústria de fertilizantes (BNDES, 2010). De forma geral, a cadeia produtiva da indústria de fertilizantes é dividida em três segmentos, conforme a seguir descritos.

1) Produção de matérias-primas e produtos intermediários: as matérias-primas básicas são produzidas a partir de recursos naturais, como a rocha fosfática (da qual se obtém concentrado fosfático), o gás natural (do qual se obtém amônia) e o enxofre (recurso natural e matéria-prima básica). Os produtos intermediários são os ácidos sulfúrico, nítrico e fosfórico.

2) Fertilizantes básicos: nesse segmento, fabricam-se os fertilizantes potássicos (sulfato de potássio e cloreto de potássio), nitrogenados (nitrato de amônia, ureia e nitrocálcio) e fosfatados (fosfato de diamônio, superfosfato simples e superfosfato triplo).

3) Misturas de formulaçóes de nitrogênio, fósforo e potássio (NPK): nesse segmento, são compradas as matérias-primas e fertilizantes básicos, e esses são misturados para se obter os fertilizantes granulados e as misturas de formulação NPK. 
O consumo de fertilizantes em 2014 - segundo os principais elementos químicos (nitrogênio, potássio e fósforo) e principais países consumidores - é apresentado na tabela 2. No geral, o Brasil foi o quarto maior consumidor mundial de NPK. Entre os elementos químicos, o país ocupou a quarta posição no consumo de nitrogênio. Essa colocação foi uma posição inferior quando se considerou o consumo de fósforo e de potássio.

TABELA 2

Consumo de fertilizantes segundo os principais elementos químicos e países, e participação do Brasil na produção mundial (2014)

\begin{tabular}{|c|c|c|c|c|c|c|c|c|}
\hline Posição & NPK & $\begin{array}{l}\text { Participação } \\
\text { (\%) }\end{array}$ & $\begin{array}{l}\text { Nitrogênio } \\
(\%)\end{array}$ & $\begin{array}{c}\text { Participação } \\
(\%)\end{array}$ & Fósforo & $\begin{array}{c}\text { Participação } \\
(\%)\end{array}$ & Potássio & $\begin{array}{c}\text { Participação } \\
(\%)\end{array}$ \\
\hline $1^{\circ}$ & China & 28 & China & 30 & China & 28 & China & 23 \\
\hline $2^{\circ}$ & Índia & 14 & Índia & 15 & Índia & 14 & Brasil & 17 \\
\hline 3o & EUA & 11 & EUA & 11 & Brasil & 11 & EUA & 14 \\
\hline $4^{\circ}$ & Brasil & 8 & Brasil & 4 & EUA & 10 & Índia & 8 \\
\hline 5o & Indonésia & 3 & Paquistão & 3 & Paquistão & 2 & Indonésia & 5 \\
\hline $\begin{array}{l}\text { Milhões de toneladas } \\
\text { de nutrientes }\end{array}$ & & 183,7 & & 109,7 & & 32,6 & & 41,4 \\
\hline \multicolumn{9}{|c|}{ Participação do Brasil (\%) } \\
\hline Consumo & & 8 & & 4 & & 14 & & 14 \\
\hline Produção & & 2 & & 1 & & 4 & & 1 \\
\hline
\end{tabular}

Fonte: IFA (2016).

A participação brasileira na produção mundial também pode ser visualizada na tabela 2. Devido à baixa participaçáo na produção mundial de fertilizantes, a dependência da agricultura brasileira de importaçôes é significativa para todos os elementos químicos, com destaque para o fósforo e o potássio. Em termos percentuais, $14 \%$ do consumo mundial desses elementos se deve à demanda brasileira; em contrapartida, apenas $4 \%$ da produção mundial de fósforo e $1 \%$ da produção de potássio são realizadas no país.

Para o ano de 2014, a relação entre produção e consumo do potássio, fósforo e nitrogênio no cenário brasileiro é apresentada no gráfico 3. Nesse ano, $92 \%$ do potássio consumido no país derivou de importações, enquanto apenas $8 \%$ foi produzido em território nacional. Quanto ao nitrogênio, as importaçóes representaram $73 \%$ e a produção $27 \%$. O fósforo apresentou a menor dependência do setor externo (46\%), sendo, em sua maioria (54\%), produzido internamente. 
GRÁFICO 3

Produção e consumo pelo mercado brasileiro, segundo os principais elementos químicos (2014)

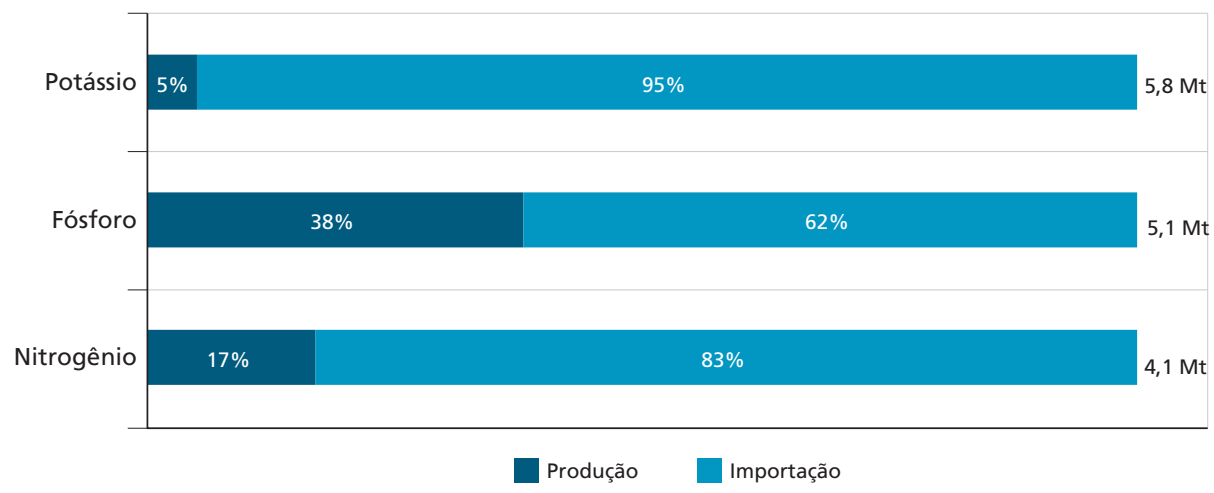

Fonte: IFA (2016).

Essa alta dependência de produtos importados tem se acentuado nos últimos anos, aumentando a exposição do país a riscos externos, como oscilações de preços no mercado internacional (gráfico 4). Conforme se verifica no gráfico 4, o deficit da relação entre produção e importação permaneceu expressivo ao longo do período de 2000 a 2016, tornando-se crescente a partir de 2009.

GRÁFICO 4

Produção interna de fertilizantes, importação e deficit (2000-2016)

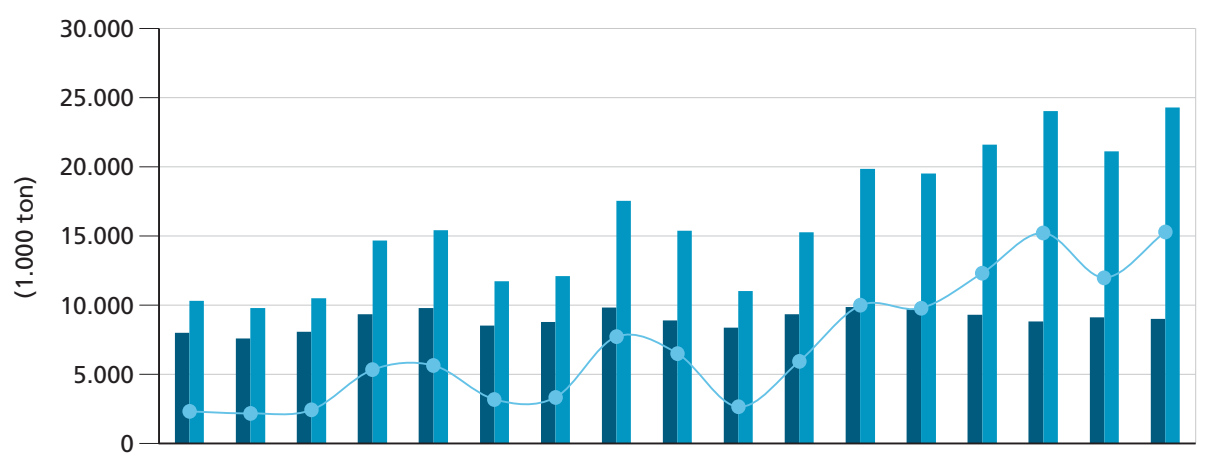

20002001200220032004200520062007200820092010201120122013201420152016

Produção Importação —Deficit

Fonte: Anda (2018).

De acordo com Benites, Polidoro e Resende (2010), a dependência externa brasileira da importação de fertilizantes voltou a ser pauta do debate depois dos movimentos que marcaram o setor agrícola entre 2007 e 2008. Segundo os autores, inicialmente frente ao vertiginoso aumento dos preços dos fertilizantes a partir do 
segundo semestre de 2007, muitos produtores, visando à proteção contra aumentos ainda maiores, adquiriram o produto pelo dobro dos preços pagos na safra anterior. Por outro lado, a partir de 2008 , os preços das commodities, bem como das matérias-primas para fertilizantes, recuaram expressivamente. Esse cenário refletiu em prejuízo importante tanto aos produtores, que haviam antecipado suas compras de fertilizantes com receio de novas altas de preços, quanto para as empresas de fertilizantes, que passaram a ter que comercializar a preços menores para reduzir estoques (Benites, Polidoro e Resende, 2010).

Com a produção doméstica de fertilizantes estagnada, a maior demanda doméstica pelo insumo, em especial a partir de 2009, passou a ser atendida por importaçóes. Diante desse cenário, agentes nacionais do setor de fertilizantes vêm projetando medidas no sentido de estimular a produção interna, reduzindo, assim, a dependência do mercado externo. Segundo dados divulgados por Anda (2018), a expectativa é que, liderados por ações da iniciativa pública e privada, os investimentos no setor superem US\$ 13 bilhóes entre 2013 e 2018. Até 2017, a projeção era de investimentos na ordem de US\$18,9 bilhóes. Esse reajuste na expectativa se deveu - segundo a a publicação - à desistência da Vale no projeto do Rio Colorado, em Mendonza, na Argentina, o que provocou uma revisão no total de investimentos projetados pelas principais empresas de fertilizantes do Brasil para os próximos anos.

Para Anda (2018), mesmo com um cenário adverso e perante revisão para baixo no total de investimentos projetados pelas principais empresas de fertilizantes do Brasil, a perspectiva é de que a produçãoo brasileira de nitrogênio, fósforo e potássio (NPK) se eleve nos próximos anos, reduzindo a dependência brasileira do produto importado de uma média 74,5\% para 54,3\%. Em termos de composição, a perspectiva do setor é que a produção de nitrogênio aumente de forma a reduzir a necessidade de importação de $76,2 \%$ para $46,2 \%$. No caso do fósforo, a expectativa é que o Brasil passe a importar $22,2 \%$ da sua demanda, contra os atuais $57,4 \%$. Para o potássio, a projeção de aumento na produção deverá reduzir a dependência de importação dos atuais $94,5 \%$ para $87,5 \%$.

Prochnow (2018) destaca que há outros desafios a serem superados pela ótica da demanda de fertilizantes, relacionados ao seu uso mais eficiente. Entre eles, o autor destaca a criação de melhores misturas de fertilizantes, a realização de mais pesquisas sobre a nutrição correta das culturas, as variações regionais e a educação dos agricultores quanto aos princípios do manejo de nutrientes (uso da fonte certa de fertilizantes, na dose, local e época corretas), a fim de maximizar a eficiência agronômica e os retornos econômicos sem prejudicar o meio ambiente. 


\section{METODOLOGIA}

\subsection{0 modelo insumo-produto}

O modelo de insumo-produto - criado a partir dos estudos de Wassily Leontief no final da década de 1930 - descreve as inter-relaçóes existentes em um sistema econômico (país, estado, região etc.) no processo de geração de riqueza.

Para Guilhoto (2009), por meio do modelo de insumo-produto, Leontief conseguiu construir uma "fotografia econômica" da própria economia; nessa fotografia, ele demonstrou como os setores estão relacionados entre si em termos de fornecimento e compra de produtos e serviços. O resultado foi uma visão única e compreensível de como a economia funciona.

Esquematicamente, as relações fundamentais de insumo-produto são apresentadas na figura 2. Nesse sistema, demonstra-se que as vendas dos setores podem ser utilizadas dentro do processo produtivo pelos diversos setores compradores da economia ou podem ser consumidas pelos diversos componentes da demanda final (famílias, governo, investimento e exportaçóes). Por outro lado, para se produzir, são necessários insumos, impostos são pagos, importam-se produtos e gera-se valor adicionado (destinado ao pagamento de salários e à remuneraçáo do capital e da terra agrícola), além de se gerar empregos (Guilhoto, 2009).

FIGURA 2

Relações fundamentais de insumo-produto de forma esquemática

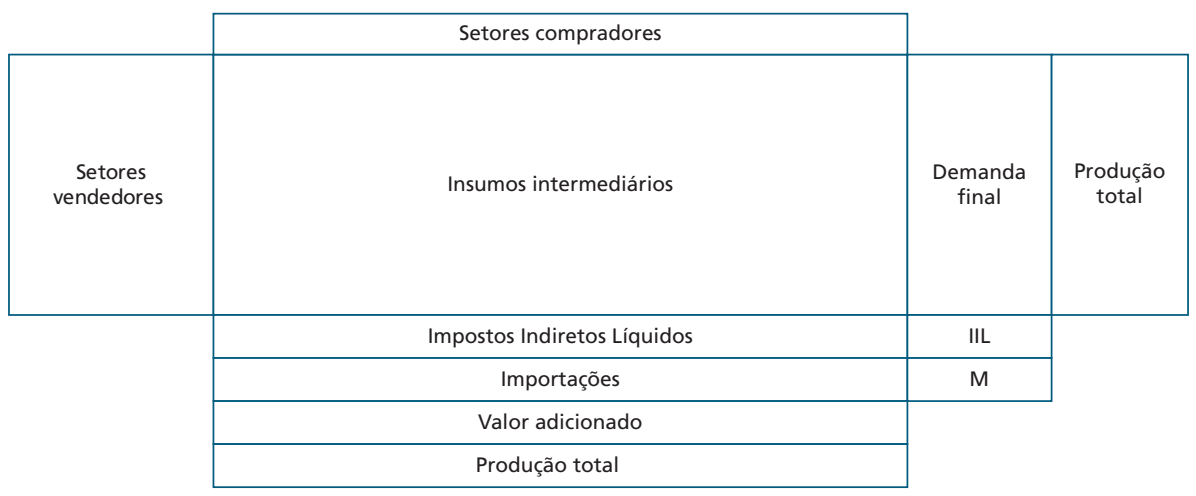

Fonte: Guilhoto (2009).

Conforme Cardoso e Guilhoto (2003), os fluxos intersetoriais no modelo de insumo-produto de Leontief são resultantes de fatores tecnológicos e econômicos, e podem ser representados por um conjunto de matrizes que expressam um sistema de equaçóes simultâneas, conforme se verifica em (1):

$X=A X+Y$, 
em que $X$ é um vetor $(n \times 1)$ do valor de produçâo total para cada setor, $Y$ é um vetor ( $n x 1)$ com os valores da demanda final setorial, e $A$ é uma matriz ( $n x n)$ com os coeficientes técnicos de produção.

Em sua forma geral, o modelo considera o vetor de demanda final como variável exógena ao sistema. Assim, o vetor de produção total é determinado apenas pelo vetor da demanda final, conforme expresso em (2) e (3):

$$
\begin{aligned}
& X=B Y \\
& B=(I-A)^{-1},
\end{aligned}
$$

em que $B$ é uma matriz $(n x n)$ que representa a matriz inversa de Leontief. Nessa matriz, estão descritos os coeficientes técnicos diretos e indiretos ou a matriz de efeitos globais, que mostra todos os efeitos sobre a economia decorrentes de mudanças quantitativas nos componentes da demanda final.

No Brasil, as matrizes de insumo-produto são geradas a partir das contas nacionais, divulgadas pelo Instituto Brasileiro de Geografia e Estatística (IBGE). Esses fluxos são mapeados por um conjunto de produtos e de atividades/setores. A estrutura econômica matricial mais ampla para o ano de 2008 é representada por 110 produtos e serviços e 57 atividades/setores, nela estão incluídas: a matriz de produção, formada por um conjunto de produtos por setores produtivos; a matriz de usos, formada por um conjunto de produtos, usuários e fontes (doméstica ou importada); uma matriz de fatores de produção, que representa os valores adicionados por indústria a preço básico; uma matriz de impostos, com dimensões produto, usuários e fonte; e uma matriz de margens de comércio e de transporte.

Para estimar a matriz $A$, e assim obter o sistema de insumo-produto para o caso brasileiro, é preciso combinar as matrizes supramencionadas. Tal procedimento envolve uma série de estratégias, descritas de forma detalhada em Guilhoto e Sesso Filho (2010).

Quanto à tecnologia de produção, vale destacar que a matriz $A$ empregada neste trabalho considera a tecnologia baseada na indústria, uma vez que, como apontado por Guilhoto (2009), essa hipótese tem maior proximidade com a realidade do que aquela da tecnologia baseada no produto - mais restritiva e, em geral, aplicada a poucos setores da economia.

\subsection{Geradores e multiplicadores}

A partir do sistema de insumo-produto e das relaçóes intersetoriais nele apresentadas, é possível calcular uma série de indicadores, que ajudam a entender as relaçóes existentes em um sistema econômico, bem como avaliar o impacto das transformaçóes dos diversos setores produtivos da economia em termos de geração de produção, renda, salários, empregos, entre outras variáveis. 
Entre os indicadores mais usualmente empregados, têm-se os chamados geradores e multiplicadores. Esses indicadores são calculados com base na matriz inversa de Leontief e permitem mensurar o impacto que as mudanças ocorridas na demanda final $(\mathrm{Y})$, ou em cada um de seus componentes (consumo das famílias, gastos do governo, investimentos e exportaçóes), teriam sobre diferentes variáveis, como produção total, emprego, importaçóes, impostos, salários, valor adicionado, entre outros (Guilhoto, 2009).

Tomando-se a matriz inversa de Leontief, apresentada na equação (3), pode-se obter, para cada setor da economia, o quanto é gerado direta e indiretamente de emprego, importaçóes, impostos, salários, valor adicionado, entre outros, para cada unidade monetária na demanda final. Tal estimativa é obtida, matematicamente, conforme (4):

$$
G V_{j}=\sum_{i=1}^{n} b_{i j} v_{i},
$$

em que $G V_{j}$ representa o impacto total, direto e indireto, sobre a variável em questão; $b_{i j}$ é o elemento da linha $i$ e da coluna $j$ da matriz inversa de Leontief; e $v_{i}$ é o coeficiente direto da variável em questáo, sendo este obtido dividindo-se, para cada setor, o valor utilizado dessas variáveis $(V i)$ pela produçáo total do setor correspondente $(X i)$, conforme expresso em (5):

$$
v_{i}=V_{i} / X_{i} .
$$

Definidos os geradores, pode-se calcular os multiplicadores, que correspondem à divisão dos geradores pelo respectivo coeficiente direto, conforme expresso em (6). Os multiplicadores indicam quanto é gerado, direta e indiretamente, de emprego, importaçóes, impostos, entre outros, para cada aumento de uma unidade monetária na demanda final.

$$
M V_{i}=G V_{i} / v_{i} .
$$

Em (6), $M V_{i}$ representara o multiplicador da variável em questão.

Neste trabalho, foram calculados multiplicadores de produção, emprego e renda. As análises dos efeitos se restringiram somente à demanda de insumos intermediários, ou seja, a demanda das famílias foi considerada exógena à demanda final. Nesse caso, os multiplicadores são classificados como do tipo I. O multiplicador tipo I capta os efeitos diretos e indiretos, e o multiplicador tipo II capta os efeitos diretos, indiretos e induzidos. A diferença entre os dois multiplicadores corresponde então ao efeito induzido pelo consumo das famílias endogeneizado ao sistema. Quando a demanda das famílias é endogenizada no sistema de equaçóes, esses multiplicadores têm a denominação de multiplicadores tipo II.

Quanto à produção, a interpretação do multiplicador corresponde ao valor total de produção adicional, verificado em toda a economia, que é necessário para satisfazer uma unidade monetária adicional na demanda final de um setor específico (Miller e Blair, 2009). 
Matematicamente, o multiplicador de produção é obtido com base na matriz inversa de Leontief $B$, sendo equivalente a soma ao longo das colunas da matriz, conforme expresso em (7):

$$
M P_{j}=\sum_{i=1}^{n} b_{i j}
$$

em que $M P j$ é o multiplicador de produção do j-ésimo setor e as outras variáveis são definidas conforme descrito anteriormente.

Os efeitos multiplicadores gerados pelos aumentos no consumo final de determinados produtos (insumos intermediários) ocasionam impactos diferenciados na economia, de forma que cada setor possui um multiplicador de produção. Nessa abordagem, o acréscimo total na produçáo é resultante de efeitos diretos - aumento da produção do setor específico - e indiretos - aumento da produção dos demais setores da economia inter-relacionados. Uma variação positiva da demanda final tem implicaçôes sobre a demanda de um setor específico, mas também impacta outros setores da economia, embora de maneira diferenciada (Cardoso e Guilhoto, 2003).

O multiplicador de emprego, por sua vez, corresponde ao número de empregos gerados e mantidos em toda a economia decorrente de uma alteração na demanda final de um determinado setor. Para cada 1 emprego gerado diretamente em um setor para atender uma alteração em sua demanda final, o multiplicador de emprego mostra quantos empregos são gerados e mantidos na economia como um todo (UFMT, 2007).

Analogamente, o multiplicador da renda corresponde à renda adicional gerada em toda a economia decorrente de uma alteraçáo na demanda final de um determinado setor. Ou, para cada $\mathrm{R} \$ 1$ em renda gerado diretamente na própria atividade para atender uma alteração na demanda final, o multiplicador de renda mostra quantos Reais em renda são gerados na economia como um todo (UFMT, 2007).

\section{3 Índices de Rasmussen-Hirschman}

Os índices de ligaçôes para trás e para frente de Rasmussen-Hirschman indicam o grau de encadeamento dos setores da economia, tanto para trás como para frente, evidenciando o grau em que um setor demanda ou oferta insumos para os demais setores do sistema econômico (Casimiro-Filho, 2002).

No primeiro caso, índices de ligaçóes para trás, estima-se o quanto um setor demanda dos demais; no segundo - índices de ligação para frente -, a estimativa refere-se a quanto esse setor é demandado pelos demais. Os setores que apresentam índices de ligação, para trás ou para frente, maiores que a unidade, são aqueles que estão acima da média em termos de capacidade de impactar os demais setores (Cardoso e Guilhoto, 2003). 
Segundo Rasmussen (1956) e Hirschman (1958), setores que apresentam pelo menos um dos índices de ligação maior que as unidades são consideradas setores-chave, na medida em que o seu crescimento ou retração é reproduzido com maior intensidade no restante da economia. McGilvray (1977) adota um critério diferente, considerando um setor como chave se esse apresentar ambos os índices, para frente e para trás, maiores do que a unidade. Neste trabalho, a identificação de setores-chave segue a interpretação de Rasmussen-Hirschman.

Os índices de ligações para trás (poder da dispersão) e os índices de ligaçôes para frente (sensibilidade da dispersáo) se baseiam nos elementos da matriz inversa de Leontief $B$, sendo determinados pelas equaçóes (8) e (9) respectivamente:

$$
\begin{aligned}
U_{j} & =\left[B_{j .} / n\right] / B^{*} \\
U_{i} & =\left[B_{i .} / n\right] / B^{*},
\end{aligned}
$$

em que $B^{*}$ é média de todos os elementos da matriz $B$; é a soma de todos os elementos de uma linha típica de $\mathrm{B}$; e $B_{j}$. é a soma de todos os elementos de uma coluna típica de B.

\section{FONTE E TRATAMENTO DOS DADOS}

Os dados empregados neste artigo foram coletados das tabelas de recursos e usos e de bens e serviços do Sistema de Contas Nacionais de 2008, divulgadas pelo IBGE (2010). A partir dessas tabelas, que contemplam cinquenta e sete setores, foi estimada a Matriz Insumo Produto para o ano de 2008, segundo metodologia descrita em Guilhoto e Sesso-Filho (2010).

Ressalta-se que a estrutura apresentada pelo IBGE náo descreve o setor de adubos e fertilizantes de forma desagregada e, desse modo, foi necessário estimá-lo. Tal procedimento envolveu a obtenção de informaçōes junto à Anda com relação à produção, importação e exportação do setor. Também foram analisados dados da Produção Industrial Anual (PIA) disponibilizados pelo IBGE (2009a). Por outro lado, os dados referentes à mão de obra empregada no setor foram obtidos junto à Relação Anual de Informaçôes Sociais - Rais (MTE, 2009). Todas essas informações se referiram ao ano de 2008, período base da matriz insumo-produto analisada.

\section{RESULTADOS E DISCUSSÕES}

A tabela 3 apresenta os principais insumos utilizados pela produção do setor agrícola no ano de 2008. Verifica-se que o conjunto de adubos e fertilizantes foi o insumo mais utilizado naquele ano, com participação relevante de $27,34 \%$ no consumo total do setor. Na sequência, vieram os insumos produzidos no próprio setor (parcela da produção que não é vendida, ficando na agricultura como insumo), os defensivos agrícolas e o comércio, todos com percentuais acima de 10\%. Essa importância do setor de fertilizantes, que se mostra determinante para o custo agrícola e, então, para 
a competitividade do setor, expressa a necessidade de se ter um setor bem estruturado internamente, e menos dependente de compras externas. Segundo Anda (2018), em 2008, 68\% da oferta doméstica de fertilizantes teve origem em importaçóes.

TABELA 3

Principais insumos nacionais usados na produção agrícola, segundo os setores da matriz de usos (2008)

\begin{tabular}{lcc}
\hline Setores & $\begin{array}{c}\text { Agricultura, silvicultura, } \\
\text { exploração florestal }\end{array}$ & $\begin{array}{c}\text { Participação no consumo } \\
\text { do setor (\%) }\end{array}$ \\
\hline Adubos e fertilizantes & 16.821 & 27,34 \\
Agricultura, silvicultura, exploração florestal & 10.344 & 16,81 \\
Defensivos agrícolas & 9.253 & 15,04 \\
Comércio & 6.490 & 10,55 \\
Refino de petróleo e coque & 4.893 & 7,95 \\
Transporte, armazenagem e correio & 3.776 & 6,14 \\
Alimentos e bebidas & 1.771 & 2,88 \\
Intermediação financeira e seguros & 1.289 & 2,10 \\
Outros produtos químicos & 1.018 & 1,65 \\
Produtos de metal - exclusive máquinas/equipamentos & 735 & 1,19 \\
Artigos de borracha e plástico & 726 & 1,18 \\
Eletricidade e gás, água, esgoto e limpeza urbana & 698 & 1,13 \\
Serviç̧os de informação & 271 & 0,44 \\
Etanol & 87 & 0,14 \\
\hline Total do grupo & $\mathbf{5 8 . 1 7 2}$ & $\mathbf{9 4 , 5 5}$ \\
Total nacional & 105.710 & $\mathbf{1 0 0 , 0 0}$ \\
\hline
\end{tabular}

Fonte: Resultados do trabalho.

Obs.: Os setores com percentuais menores que $1 \%$ foram desconsiderados.

Os dados da tabela 3 explicitam a importância dos fertilizantes para o custo de produção agrícola, e então para a competitividade desse setor. Segundo Gilio e Castro (2018), entre 1996 e 2017, enquanto o volume de produção do agronegócio (PIB-volume) expandiu 49,4\%, os preços relativos do setor se desvalorizaram $36,2 \%$, de modo que a renda real auferida pelos agentes envolvidos nas diversas atividades do agronegócio retraiu 4,7\% (mesmo com a expansão expressiva de produção). Para esses autores, além da redução dos preços dos produtos finais do agronegócio, levou a esse resultado o aumento dos custos de produção - que pressionou sobretudo a agropecuária. Nesse contexto, os autores destacam o aumento e a volatilidade dos preços dos fertilizantes e defensivos, fato que estaria relacionado à dependência de importaçóes.

Os resultados para os multiplicadores de produção, em ordem de importância na economia brasileira, são apresentados na tabela 4 . 
TABELA 4

Multiplicadores de produção

\begin{tabular}{|c|c|c|c|c|c|}
\hline Setores & Posição & Multiplicador & Setores & Posição & Multiplicador \\
\hline Alimentos e Bebidas & 10 & 2,448 & Têxteis & $30 \circ$ & 1,954 \\
\hline Automóveis, camionetas e utilitários & 20 & 2,424 & Móveis e produtos das indústrias diversas & 310 & 1,943 \\
\hline Caminhões e ônibus & 3은 & 2,421 & Álcool & $32 \circ$ & 1,937 \\
\hline Refino de petróleo e coque & $4^{\circ}$ & 2,352 & Pecuária e pesca & $33^{\circ}$ & 1,906 \\
\hline Outros Produtos químicos & 5은 & 2,323 & Outros da indústria extrativa & $34^{\circ}$ & 1,900 \\
\hline Defensivos agrícolas & 60 & 2,305 & Artigos do vestuário e acessórios & $35^{\circ}$ & 1,897 \\
\hline Fabricação de resina e elastômeros & 70 & 2,277 & Transporte, armazenagem e correio & $36 \div$ & 1,794 \\
\hline Produtos do fumo & $8^{\circ}$ & 2,216 & Produtos farmacêuticos & $37 \stackrel{0}{0}$ & 1,789 \\
\hline Artefatos de couro e calçados & 9o & 2,214 & Construção & $38^{\circ}$ & 1,774 \\
\hline Peças e acessórios para automotores & $10^{\circ}$ & 2,188 & Jornais, revistas, discos & $39 \circ$ & 1,768 \\
\hline $\begin{array}{l}\text { Material eletrônico e equipamento } \\
\text { de comércio }\end{array}$ & $11 \stackrel{0}{0}$ & 2,175 & Petróleo e gás natural & $40^{\circ}$ & 1,725 \\
\hline Cimento & $12^{0}$ & 2,160 & Eletricidade e gás, água/esgoto/limpeza & $41 \stackrel{0}{2}$ & 1,724 \\
\hline $\begin{array}{l}\text { Produtos e preparados químicos } \\
\text { diversos }\end{array}$ & 130 & 2,158 & $\begin{array}{l}\text { Serviços prestados às famílias e } \\
\text { associativas }\end{array}$ & $42^{\circ}$ & 1,721 \\
\hline Tintas, vernizes, esmaltes e lacas & $14^{\circ}$ & 2,148 & Serviços de informação & $43^{\circ}$ & 1,691 \\
\hline Metalurgia de metais não-ferrosos & $15^{\circ}$ & 2,137 & $\begin{array}{l}\text { Agricultura, silvicultura, exploração } \\
\text { florestal }\end{array}$ & $44^{\circ}$ & 1,678 \\
\hline Perfumaria, higiene e limpeza & 160 & 2,132 & Saúde mercantil & $45^{\circ}$ & 1,674 \\
\hline Artigos de borracha e plástico & $17 \stackrel{0}{0}$ & 2,128 & Minério de ferro & $46^{\circ}$ & 1,668 \\
\hline Eletrodomésticos & $18^{\circ}$ & 2,124 & $\begin{array}{l}\text { Aparelhos médico-hospitalar, medida/ } \\
\text { óptico }\end{array}$ & $47 \stackrel{-}{0}$ & 1,640 \\
\hline Outros equipamentos de transporte & 190 & 2,122 & Serviços prestados às empresas & $48^{\circ}$ & 1,564 \\
\hline Adubos e fertilizantes & $20^{\circ}$ & 2,117 & Educação mercantil & 490 & 1,562 \\
\hline Celulose e produtos de papel & 219 & 2,106 & Saúde pública & 50 & 1,533 \\
\hline $\begin{array}{l}\text { Máquinas, aparelhos e materiais } \\
\text { elétricos }\end{array}$ & $22^{\circ}$ & 2,094 & Administração pública e seguridade social & $51 \stackrel{0}{1}$ & 1,523 \\
\hline $\begin{array}{l}\text { Máquinas e equipamentos - } \\
\text { inclusive manutenção/reparos }\end{array}$ & $23^{\circ}$ & 2,087 & Intermediação financeira e seguros & $52^{\circ}$ & 1,522 \\
\hline Fabricação de aço e derivados & $24^{\circ}$ & 2,048 & Comércio & $53^{\circ}$ & 1,431 \\
\hline $\begin{array}{l}\text { Máquinas de escritório e } \\
\text { equipamentos de informáica }\end{array}$ & 250 & 2,034 & Serviços de manutenção e reparação & $54^{\circ}$ & 1,389 \\
\hline $\begin{array}{l}\text { Produtos de metal - exclusive } \\
\text { máquinas/equipamentos }\end{array}$ & 26 & 1,986 & Educação pública & $55^{\circ}$ & 1,359 \\
\hline $\begin{array}{l}\text { Outros produtos minerais não- } \\
\text { metálicos }\end{array}$ & $27 \stackrel{0}{0}$ & 1,968 & Serviços imobiliários e aluguel & $56^{\circ}$ & 1,112 \\
\hline $\begin{array}{l}\text { Produtos de madeira - exclusive } \\
\text { móveis }\end{array}$ & $28^{\circ}$ & 1,960 & Serviços domésticos & $57 \stackrel{0}{2}$ & 1,000 \\
\hline $\begin{array}{l}\text { Serviços de alojamento e } \\
\text { alimentação. }\end{array}$ & $29 \stackrel{0}{0}$ & 1,956 & & & \\
\hline
\end{tabular}

Fonte: Resultados do trabalho. 
No caso dos fertilizantes, o multiplicador calculado indicou que foram gerados $R$ \$ 2,117 na economia brasileira para cada $R$ \$ 1,00 de produção gerado no setor de fertilizantes em 2008, considerando-se os efeitos diretos e indiretos (tabela 4). Conforme apontado por Figueiredo et al. (2011), tal resultado indica que o setor de fertilizantes tem um efeito mais que proporcional na economia. Esse resultado conferiu ao setor de fertilizantes o vigésimo lugar no ranking dos setores com os maiores efeitos multiplicadores de produção, entre os 57 setores da economia considerados.

Entre os setores com efeitos mais que proporcionais na economia - aqueles com multiplicadores superiores a 2,00 -, destacam-se os setores da indústria de transformação, sobretudo relacionados à produção de alimentos e de automóveis. Esse resultado está em linha com os encontrados por Figueiredo et al. (2011), Amorim, Coronel e Teixeira (2009) e Santos et al. (2009). Figueiredo et al. (2011), que analisam os indicadores obtidos de uma matriz de insumo-produto para o Mato Grosso em 2007, encontraram multiplicadores de produção tipo I superiores a 2,40 para as indústrias de outros produtos alimentares, de abate de frangos, suínos e bovinos, de raçôes e de fabricação de óleos vegetais. Por sua vez, Amorim, Coronel e Teixeira (2009) analisam o Brasil como um todo com foco na agropecuária, utilizando a matriz insumo-produto de 2005 e o nível de desagregação de atividades de seçôes da Classificação Nacional de Atividades Econômicas (CNAE). Segundo os resultados encontrados, o setor com maior multiplicador de produção em 2005 foi a indústria de transformação. Santos et al. (2009) analisaram o estado de Minas Gerais, com foco na indústria do café e utilizaram a matriz-insumo produto de 1995. Os resultados encontrados por esses apontaram que os setores com maiores multiplicadores de produção foram os de produtos não-metálicos, siderurgia e metalurgia, a indústria do café e outras indústrias de produtos alimentares.

Os menores valores encontrados para o multiplicador de produção estiveram relacionados, em sua maioria, aos setores de serviços. Esse resultado também está em linha com o encontrado por Pereira, Bastos e Perobelli (2013), Amorim, Coronel e Teixeira (2009) e Santos et al. (2009). Pereira, Bastos e Perobelli (2013) utilizaram a matriz insumo-produto de 2005, com foco específico no setor de serviços. Segundo esses autores, os setores de serviços ocupam as últimas posições no ranking dos setores econômicos com maiores multiplicadores de produçáo, revelando que as atividades de serviços têm baixo desempenho em termos de geração de produção na economia.

Então, considerando a literatura e os resultados expostos na tabela 4, verifica-se que a indústria de fertilizantes tem relativamente alto potencial de geração de produção em resposta a variações na demanda agregada, similar ao das demais industrias de transformação. 
$\mathrm{Na}$ tabela 5, estão apresentados os multiplicadores de emprego, calculados para todos os setores da economia brasileira no ano de 2008. O setor de refino de petróleo apresentou o maior multiplicador, com valor expressivamente superior ao do multiplicador da indústria de produtos do fumo, segunda colocada no ranking. Especificamente, nesse setor, para cada emprego gerado para atender a um choque na demanda final, são necessários aproximadamente 61 empregos adicionais na economia.

Quanto ao setor de fertilizantes, o multiplicador de emprego foi de 13,583, o que corresponde ao número de empregos gerados e mantidos na economia brasileira frente a um choque na demanda final do setor. De outra forma, para cada emprego gerado diretamente no setor de fertilizantes para atender uma alteração na demanda final do setor, o multiplicador de emprego mostrou que 13,583 empregos adicionais são criados e mantidos na economia como um todo.

TABELA 5

Multiplicadores de emprego

\begin{tabular}{|c|c|c|c|c|c|}
\hline Setor & Posição & Multiplicador & Setor & Posição & Multiplicador \\
\hline Refino de petróleo e coque & 10 & 60,84 & Artigos de borracha e plástico & 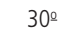 & 2,46 \\
\hline Produtos do fumo & 20 & 20,69 & Serviços de informação & $31^{\circ}$ & 2,03 \\
\hline Petróleo e gás natural & 30 & 18,37 & $\begin{array}{l}\text { Produtos de madeira - exclusive } \\
\text { móveis }\end{array}$ & $32^{\circ}$ & 2,01 \\
\hline Caminhões e ônibus & 40 & 17,48 & Outros da indústria extrativa & $33^{\circ}$ & 2,00 \\
\hline Automóveis, camionetas e utilitários & 50 & 14,83 & Jornais, revistas, discos & $34^{\circ}$ & 1,89 \\
\hline Adubos e fertilizantes & $6^{0}$ & 13,58 & Artefatos de couro e calçados & $35^{\circ}$ & 1,87 \\
\hline Defensivos agrícolas & 70 & 13,39 & Têxteis & $36^{\circ}$ & 1,76 \\
\hline Fabricação de resina e elastômeros & 80 & 10,91 & $\begin{array}{l}\text { Outros produtos de minerais não- } \\
\text {-metálicos }\end{array}$ & $38^{\circ}$ & 1,74 \\
\hline Cimento & 9o & 8,38 & Aparelhos médico-hospitalar e óptico & 370 & 1,74 \\
\hline Outros produtos químicos & $10^{0}$ & 8,14 & $\begin{array}{l}\text { Produtos de metal - exclusive máqui- } \\
\text { nas e equipamentos }\end{array}$ & 390 & 1,74 \\
\hline Fabricação de aço e derivados & 110 & 8,10 & Serviços imobiliários e aluguel & 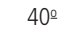 & 1,69 \\
\hline Minério de ferro & $12^{\circ}$ & 7,89 & $\begin{array}{l}\text { Móveis e produtos das indústrias } \\
\text { diversas }\end{array}$ & $41^{\circ}$ & 1,61 \\
\hline Alimentos e bebidas & 130 & 6,95 & $\begin{array}{l}\text { Administração pública e seguridade } \\
\text { social }\end{array}$ & $42^{\circ}$ & 1,57 \\
\hline Álcool & $14^{\circ}$ & 6,34 & Serviços de alojamento e alimentação & $43^{\circ}$ & 1,56 \\
\hline $\begin{array}{l}\text { Máquinas para escritório e equipa- } \\
\text { mentos de informática }\end{array}$ & 150 & 5,94 & Transporte, armazenagem e correio & $44^{\circ}$ & 1,55 \\
\hline $\begin{array}{l}\text { Material eletrônico e equipamento } \\
\text { comum }\end{array}$ & 160 & 5,69 & Saúde mercantil & $45^{\circ}$ & 1,54 \\
\hline Celulose e produtos de papel & 170 & 5,10 & Saúde pública & $46^{\circ}$ & 1,52 \\
\hline Perfumaria, higiene e limpeza & 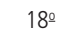 & 4,56 & Pecuária e pesca & $47 \stackrel{0}{2}$ & 1,39 \\
\hline Tintas, vernizes, esmaltes e lacas & $19 \circ$ & 4,45 & Artigos do vestuário e acessórios & $48^{\circ}$ & 1,38 \\
\hline
\end{tabular}




\begin{tabular}{|c|c|c|c|c|c|}
\hline Setor & Posição & Multiplicador & Setor & Posição & Multiplicador \\
\hline Produtos farmacêuticos & 20 & 4,22 & Construção & $49 \circ$ & 1,36 \\
\hline Metalurgia de metais não-ferrosos & 210 & 4,01 & Serviços prestados às empresas & $50^{\circ}$ & 1,31 \\
\hline Outros equipamentos de transporte & $22^{\circ}$ & 3,90 & Serviços às famílias e associativas & 510 & 1,30 \\
\hline Eletrodomésticos & 230 & 3,51 & Educação mercantil & $52^{\circ}$ & 1,29 \\
\hline $\begin{array}{l}\text { Eletricidade/gás/água/esgoto/limpeza } \\
\text { urbana }\end{array}$ & $24^{\circ}$ & 3,35 & Educação pública & $53^{\circ}$ & 1,21 \\
\hline $\begin{array}{l}\text { Peças e acessórios para veículos } \\
\text { automotivos }\end{array}$ & $25^{\circ}$ & 3,24 & Comércio & $54^{\circ}$ & 1,18 \\
\hline $\begin{array}{l}\text { Produtos e preparados químicos } \\
\text { diversos }\end{array}$ & $26^{\circ}$ & 3,03 & $\begin{array}{l}\text { Agricultura, silvicultura, explorção } \\
\text { florestal }\end{array}$ & $55^{\circ}$ & 1,15 \\
\hline Intermediação financeira e seguros & 270 & 2,94 & Serviços de manutenção e reparação & $56^{\circ}$ & 1,07 \\
\hline $\begin{array}{l}\text { Máquinas, aparelhos e materiais } \\
\text { elétricos }\end{array}$ & 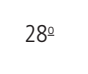 & 2,86 & Serviços domésticos & 570 & 1,00 \\
\hline $\begin{array}{l}\text { Máquinas e equipamentos - inclusive } \\
\text { manutenção/reparos }\end{array}$ & 290 & 2,71 & & & \\
\hline
\end{tabular}

Fonte: Resultados do trabalho.

Nesse sentido, mesmo não se destacando em termos de geração direta de postos de trabalho - em 2008, foram registrados 21,389 mil empregos formais na atividade de fabricação de fertilizantes, apenas $0,05 \%$ dos empregos formais no país (MTE, 2009) -, o setor de fertilizantes se encontra entre os principais setores da economia em termos de capacidade de multiplicação de empregos, ocupando o sexto lugar no ranking.

Cabe destacar o desempenho dos setores da agricultura e pecuária, cujos comportamentos se refletem sobre o setor de fertilizantes. Embora esses setores sejam responsáveis por um contingente expressivo de empregos diretos, apresentaram baixa capacidade de multiplicação do emprego na economia. Especificamente, segundo dados da Pesquisa Nacional por Amostra de Domicílios - PNAD (IBGE, 2009b), a agropecuária respondeu em 2008 por $17,6 \%$ do total de 93,4 milhóes de pessoas ocupadas na economia. E, conforme se observa na tabela 5 , no caso da agricultura, para cada emprego gerado diretamente na atividade, são gerados 1,15 empregos adicionais na economia; para pecuária, este coeficiente é de 1,38. Conforme esses coeficientes, a agricultura e a pecuária estáo entre as atividades com menor capacidade de multiplicação de empregos. Esses resultados corroboram os encontrados por Amorim, Coronel e Teixeira (2009), que classificaram a agropecuária como décima colocada em termos de multiplicação de empregos, entre os doze setores analisados.

Como destacado por Figueiredo et al. (2011), esse resultado se relaciona à baixa produtividade do trabalho na agricultura e pecuária. Por se tratarem de atividades relativamente intensivas em mão de obra, a produção por pessoa empregada é baixa 
(na comparação com atividades produtivas com maior padrão de automação). Isso explica a pequena quantidade de empregos gerados no restante da economia para cada emprego adicional gerado na própria atividade.

De forma similar, comparando-se os resultados das tabelas 4 e 5 , verificam-se quedas no ranking para algumas agroindústrias quando se avalia o multiplicador de empregos (em comparação com o multiplicador de produção), como a produção de alimentos e bebidas, de artefatos de couro e calçados, de produtos de madeira, de têxteis e de artigos do vestuário e acessórios. Essas indústrias são conhecidas por apresentarem menores níveis de produtividade em relação a outras indústrias de transformação, sendo trabalho-intensivas (Saboia e Kubrusly, 2008).

O perfil da agropecuária e das indústrias de transformação de menor tecnologia contrasta com o do setor de fertilizantes, que é pouco intensivo em mão de obra, apresentando então um relativamente maior valor de produção por pessoa empregada. Segundo Barros et al. (2016), indústrias como a de fertilizantes são, em grande medida, caracterizadas como misturadoras de matérias-primas importadas e, logo, pouco intensivas em máo de obra. Para Figueiredo et al. (2011), indústrias com elevado padrão de automatização geram um grande volume de produção para cada pessoa empregada, de modo que, para cada emprego adicional gerado na referida indústria, há uma elevada geração de empregos no restante da economia perfil refletido no elevado multiplicador de emprego.

Os multiplicadores de renda são apresentados na tabela 6. O setor de fertilizantes ocupou o 12 일 luar entre os setores da economia brasileira com maiores multiplicadores, indicando que foram gerados $\mathrm{R} \$ 2,91$ na economia como um todo para cada $\mathrm{R} \$ 1,00$ gerado de renda diretamente no próprio setor, no ano de 2008. De outra forma, para cada $\mathrm{R} \$ 1,00$ de renda gerado no setor de fertilizantes, é gerado quase o triplo de renda na economia brasileira. Esse resultado indica que o setor é responsável por um elevado efeito multiplicador de renda na economia. Segundo Figueiredo et al. (2011), essa é uma característica intrínseca de setores intensivos em capital. 
TABELA 6

Multiplicadores da renda

\begin{tabular}{|c|c|c|c|c|c|}
\hline Setores & Posição & Multiplicador & Setores & Posição & Multiplicador \\
\hline Refino de petróleo e coque & 10 & 28,47 & $\begin{array}{l}\text { Produtos de metal - exclusive máquinas/ } \\
\text { equipamentos }\end{array}$ & 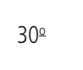 & 2,00 \\
\hline Automóveis, camionetas e utilitários & 20 & 5,93 & Artigos do vestuário e acessórios & 310 & 1,98 \\
\hline Caminhões e ônibus & 30 & 5,31 & Outros da indústria extrativa & 32 & 1,94 \\
\hline Alimentos e bebidas & 40 & 4,75 & Móveis e produtos das indústrias diversas & $33^{\circ}$ & 1,92 \\
\hline $\begin{array}{l}\text { Material eletrônico equipamentos de } \\
\text { comunicação }\end{array}$ & 50 & 4,63 & Serviços de alojamento e alimentação & $34^{\circ}$ & 1,89 \\
\hline Fabricação de resina e elastômeros & 60 & 4,59 & Produtos farmacêuticos & $35^{\circ}$ & 1,75 \\
\hline Outros produtos químicos & 70 & 4,11 & Pecuária e pesca & $36^{\circ}$ & 1,73 \\
\hline Defensivos agrícolas & 80 & 3,90 & Serviços de informação & 370 & 1,70 \\
\hline $\begin{array}{l}\text { Máquinas para escritório e equipamentos } \\
\text { de informático }\end{array}$ & 9은 & 3,82 & Petróleo e gás natural & $38^{\circ}$ & 1,70 \\
\hline Produtos do fumo & $10^{\circ}$ & 3,75 & Eletricidade/gás/água/esgoto/limpeza urbana & 390 & 1,69 \\
\hline Cimento & 110 & 3,02 & Serviços prestados às famílias e associativas & $40^{\circ}$ & 1,65 \\
\hline Adubos e fertilizantes & $12^{\circ}$ & 2,91 & Transporte, armazenagem e correio & $41^{\circ}$ & 1,65 \\
\hline Outros equipamentos de transporte & 130 & 2,90 & Jornais, revistas, discos & 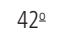 & 1,65 \\
\hline Metalurgia de metais não-ferrosos & $14^{\circ}$ & 2,88 & Construção & 430 & 1,61 \\
\hline Produtos e preparados químicos diversos & $15^{\circ}$ & 2,86 & Saúde mercantil & $44^{\circ}$ & 1,59 \\
\hline Peças e acessórios para veículos auto. & 160 & 2,71 & Minério de ferro & $45^{\circ}$ & 1,54 \\
\hline Eletrodomésticos & 170 & 2,66 & $\begin{array}{l}\text { Aparelho/instrumento médico-hospitalar, } \\
\text { óptico }\end{array}$ & $46^{0}$ & 1,49 \\
\hline Perfumaria, higiene e limpeza & 180 & 2,63 & Serviços prestados às empresas & 470 & 1,47 \\
\hline Artefatos de couro e calçados & $19 \circ$ & 2,62 & Educação mercantil & $48^{\circ}$ & 1,46 \\
\hline Celulose e produtos de papel & 20 은 & 2,59 & Intermediação financeira e seguros & 490 & 1,46 \\
\hline Fabricação de aço e derivados & 210 & 2,53 & Agricultura/silvicultura, exploração florestal & 50 은 & 1,45 \\
\hline Máquinas, aparelhos e materiais elétricos & $22 \div$ & 2,53 & Administração pública e seguridade social & 510 & 1,43 \\
\hline Tintas, vernizes, esmaltes e lacas & 230 & 2,49 & Saúde pública & $52^{\circ}$ & 1,43 \\
\hline $\begin{array}{l}\text { Máquinas/equipamento - inclusive } \\
\text { manutenção/reparos }\end{array}$ & $24 \div$ & 2,45 & Comércio & 53 & 1,31 \\
\hline Artigos de borracha e plástico & $25^{\circ}$ & 2,41 & Educação pública & $54^{\circ}$ & 1,23 \\
\hline $\begin{array}{l}\text { Outros produtos de minerais não } \\
\text { metálicos }\end{array}$ & $26^{\circ}$ & 2,15 & Serviços de manutenção e reparação & $55^{\circ}$ & 1,21 \\
\hline Têxteis & 270 & 2,08 & Serviços imobiliários e aluguel & 560 & 1,06 \\
\hline Produtos de madeira - exclusive móveis & $28^{\circ}$ & 2,04 & Serviços domésticos & $57^{\circ}$ & 1,00 \\
\hline Álcool & $29 \circ$ & 2,04 & & & \\
\hline
\end{tabular}

Fonte: Resultados do trabalho. 
Além da indústria de fertilizantes, entre os demais setores com relativamente altos multiplicadores de renda, destacam-se atividades das indústrias extrativa e de transformação. Amorim, Coronel e Teixeira (2009) identificaram que a indústria de transformação, a extrativa e as atividades imobiliárias e de aluguel apresentaram os maiores multiplicadores de renda em 2005, em linha com os resultados desta pesquisa.

Segundo Figueiredo et al. (2011), a capacidade de geração de renda de um setor depende da quantidade de pessoas ocupadas e do nível de salários pago pelo próprio setor, assim como do número de ocupados e dos salários daqueles setores com ele diretamente relacionados. O reduzido número de empregos diretos no setor de fertilizantes ajuda então a explicar a posição relativamente mais baixa desse setor no ranking dos multiplicadores de renda, em comparação com o ranking dos multiplicadores de emprego.

Considerando os três diferentes multiplicadores, o setor de fertilizantes ocupou as $20^{\underline{a}}$, 6 e $12^{\underline{a}}$ posiçóes nos rankings para os multiplicadores de produção, emprego e renda, respectivamente. Portanto, o setor de fertilizantes pode ser considerado dinâmico principalmente em termos da sua capacidade de geração de emprego e renda, mas também de produção na economia brasileira. Esse desempenho é reflexo do perfil da indústria, caracterizada pelo pequeno número de empregos diretos e por ser pouco intensiva no fator trabalho, com consequente alto nível de produção por pessoa empregada.

$\mathrm{Na}$ tabela 7, são apresentados os resultados para os índices de ligação de Rasmussen-Hirschman. Como destacado por Guilhoto (2009), a partir dos índices de ligação consegue-se estabelecer quais os setores que teriam maior poder de encadeamento dentro da economia: os índices de ligação para trás determinam o quanto um setor demanda dos outros setores, e os índices de ligação para frente determinam o quanto um determinado setor é demandado pelos outros.

Quanto aos índices de ligação para trás (poder de dispersão), observa-se que quinze atividades econômicas se destacaram com valores maiores do que um, evidenciando a importância desses setores enquanto compradores de produtos e serviços dos demais setores da economia. O setor de fertilizantes apresentou índice de dispersão de 0,810 . Tal resultado indica que, embora abaixo da média, o setor manteve-se entre os vinte com maior índice de ligação para trás. 
TABELA 7

Índices de ligação para trás e para frente de Rasmussen-Hirschman

\begin{tabular}{|c|c|c|c|c|}
\hline \multirow{2}{*}{ Setores } & \multicolumn{2}{|c|}{ Para trás } & \multicolumn{2}{|c|}{ Para frente } \\
\hline & Posição & Coeficiente & Posição & Coeficiente \\
\hline Comércio & 10 & 2,380 & $53^{\circ}$ & 0,750 \\
\hline Transporte, armazenagem e correio & 20 & 2,070 & $36^{\circ}$ & 0,940 \\
\hline Intermediação financeira e seguros & 3은 & 1,860 & $52^{\circ}$ & 0,800 \\
\hline Refino de petróleo e coque & $4^{\circ}$ & 1,830 & $4^{\circ}$ & 1,240 \\
\hline Serviços prestados às empresas & 50 & 1,800 & $48^{\circ}$ & 0,820 \\
\hline Eletricidade/gás/água/esgoto e limpeza urbana & 60 & 1,730 & 410 & 0,910 \\
\hline Serviços de informação & 7음 & 1,500 & $43^{\circ}$ & 0,890 \\
\hline Agricultura, silvicultura, exploração florestal & $8^{\circ}$ & 1,480 & $44^{\circ}$ & 0,880 \\
\hline Outros produtos químicos & 9o & 1,450 & 5웅 & 1,220 \\
\hline Petróleo e gás natural & $10^{\circ}$ & 1,450 & $40^{\circ}$ & 0,910 \\
\hline Fabricação de aço e derivados & $11^{\circ}$ & 1,390 & $24^{\circ}$ & 1,800 \\
\hline Alimentos e Bebidas & $12^{\circ}$ & 1,110 & 10 & 1,290 \\
\hline Produtos de metal - exclusive máquinas e equipamentos & $13 ㅇ$ & 1,030 & 260 & 1,040 \\
\hline Peças e acessórios para veículos automotores & $14^{\circ}$ & 1,030 & $10^{\circ}$ & 1,150 \\
\hline Artigos de borracha e plástico & $15^{\circ}$ & 1,020 & 170 & 1,120 \\
\hline Fabricação de resina e elastômeros & $16^{0}$ & 0,950 & 7음 & 1,200 \\
\hline Celulose e produtos de papel & 17 은 & 0,900 & 210 & 1,110 \\
\hline Têxteis & 180 & 0,850 & 30 & 1,030 \\
\hline Máquinas, aparelhos e materiais elétricos & $19 \underline{0}$ & 0,820 & $22^{\circ}$ & 1,100 \\
\hline Adubos e fertilizantes & $20^{\circ}$ & 0,810 & $20^{\circ}$ & 1,110 \\
\hline Metalurgia de metais não-ferrosos & 210 & 0,770 & 150 & 1,120 \\
\hline Máquinas e equipamentos - inclusive manutenção/reparos & $22^{\circ}$ & 0,760 & 23 & 1,100 \\
\hline Serviços imobiliários e aluguel & $23^{\circ}$ & 0,750 & $56^{\circ}$ & 0,580 \\
\hline Outros da indústria extrativa & $24^{\circ}$ & 0,750 & $34^{\circ}$ & 1,000 \\
\hline Produtos de madeira - exclusive móveis & $25^{\circ}$ & 0,710 & $28^{\circ}$ & 1,030 \\
\hline Pecuária e pesca & $26^{\circ}$ & 0,710 & $33^{\circ}$ & 1,000 \\
\hline Produtos e preparados químicos diversos & $27 \stackrel{\circ}{2}$ & 0,690 & $13^{\circ}$ & 1,130 \\
\hline Outros produtos de minerais não metálicos & $28^{\circ}$ & 0,690 & $27^{\circ} \stackrel{0}{2}$ & 1,300 \\
\hline Jornais, revistas, discos & 290 & 0,680 & 390 & 0,930 \\
\hline Defensivos agrícolas & 30 은 & 0,670 & 60 & 1,210 \\
\hline Material eletrônico e equip. de comunicações & 310 & 0,660 & 110 & 1,140 \\
\hline Construção & $32^{\circ}$ & 0,630 & $38^{\circ}$ & 0,930 \\
\hline Serviços prestados às famílias e associativas & $33^{\circ}$ & 0,610 & $42^{\circ}$ & 0,900 \\
\hline Álcool & $34^{\circ}$ & 0,600 & $32^{\circ}$ & 1,020 \\
\hline Minério de ferro & $35^{\circ}$ & 0,590 & $46^{\circ}$ & 0,880 \\
\hline
\end{tabular}


(Continuação)

\begin{tabular}{|c|c|c|c|c|}
\hline \multirow{2}{*}{ Setores } & \multicolumn{2}{|c|}{ Para trás } & \multicolumn{2}{|c|}{ Para frente } \\
\hline & Posição & Coeficiente & Posição & Coeficiente \\
\hline Outros equipamentos de transporte & $36^{0}$ & 0,590 & 190 & 1,120 \\
\hline Serviços de manutenção e reparação & $37^{\circ}$ & 0,570 & $54^{\circ}$ & 0,730 \\
\hline Administração pública e seguridade social & $38^{\circ}$ & 0,570 & $51^{\circ}$ & 0,800 \\
\hline Artefatos de couro e calçados & 39은 & 0,560 & 9요 & 1,160 \\
\hline Serviços de alojamento e alimentação & 40 & 0,560 & 290 & 1,030 \\
\hline Cimento & $41^{\circ}$ & 0,520 & $12^{\circ}$ & 1,140 \\
\hline Móveis e produtos das indústrias diversas & $42^{\circ}$ & 0,520 & 310 & 1,020 \\
\hline Tintas, vernizes, esmaltes e lacas & 430 & 0,510 & $14^{\circ}$ & 1,130 \\
\hline Perfumaria, higiene e limpeza & $44^{\circ}$ & 0,510 & 160 & 1,120 \\
\hline Produtos farmacêuticos & $45^{\circ}$ & 0,500 & 370 & 0,940 \\
\hline Caminhões e ônibus & $46^{0}$ & 0,490 & 30 & 1,270 \\
\hline Aparelhos/instrumentos médico-hospitalar e óptico & $47 \underline{0}$ & 0,480 & 470 & 0,860 \\
\hline Máquinas para escritório e equipamentos de informática & 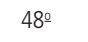 & 0,480 & 250 & 1,070 \\
\hline Automóveis, camionetas e utilitários & 490 & 0,470 & 20 & 1,270 \\
\hline Saúde mercantil & 50 은 & 0,470 & $45^{\circ}$ & 0,880 \\
\hline Artigos do vestuário e acessórios & $51^{\circ}$ & 0,470 & $35^{\circ}$ & 1,000 \\
\hline Educação mercantil & $52^{\circ}$ & 0,470 & 490 & 0,820 \\
\hline Eletrodomésticos & 530 & 0,460 & 180 & 1,120 \\
\hline Produtos do fumo & $54^{\circ}$ & 0,460 & 80 & 1,170 \\
\hline Educação pública & $55^{\circ}$ & 0,450 & $55^{\circ}$ & 0,710 \\
\hline Saúde pública & $56^{0}$ & 0,450 & $50^{\circ}$ & 0,810 \\
\hline Serviços domésticos & $57 ㅇ$ & 0,450 & $57 ㅇ$ & 0,530 \\
\hline
\end{tabular}

Fonte: Resultados do trabalho.

Conforme se observa na tabela 7 , entre os setores com maiores índices de ligação para trás, destacam-se atividades da indústria extrativa, algumas atividades da indústria de transformação, a agricultura, e algumas atividades de serviços, como comércio, transporte e intermediação financeira.

Amorim, Coronel e Teixeira (2009) também encontraram índices de ligação para trás maiores que a unidade para as indústrias extrativas e de transformação (1,41 e 1,31, respectivamente), para a agropecuária $(1,08)$, e para os serviços de transporte, armazenamento e correio $(1,10)$. Segundo esses autores, a indústria de transformação é muito expressiva no sentido em que utiliza a produção de muitos outros setores como insumo. Por outro lado, eles encontraram um índice de apenas 0,86 para o comércio, em contraste com o resultado da tabela 7. Por outro lado, Pereira, Bastos e Perobelli (2013) apontaram que, em 2005, apenas três dos 25 setores com índices de ligação para trás superior à unidade relacionavam-se a serviços, sendo eles comércio e transporte (ferroviário, metroviário) e transporte aquaviário em linha com os altos índices encontrados nesse trabalho para comércio e transporte. 
O índice de ligaçóes para frente, que mede a importância dos setores como ofertantes de produção na economia, apontou que 35 setores apresentaram valores maiores do que 1 . O setor de fertilizantes, especificamente, apresentou indicador de 1,11, o que indica o poder de encadeamento para frente desse setor, ou seja, sua importância como ofertante de produção para os demais setores da economia (tabela 7).

Novamente, no que tange aos índices de ligação para frente, as indústrias extrativas e de transformação se destacaram no ranking (tabela 7). Pereira, Bastos e Perobelli (2013) também encontraram valores baixos para os índices de ligação para a frente em diversas atividades de serviços. Segundo esses autores, para os serviços, os índices de ligação para trás são, em geral, maiores que os índices de ligação para frente, indicando que esses setores consomem maior quantidade de insumos dos outros setores, mas fornecem uma menor quantidade de insumos para os demais setores.

Considerando-se a proposição de Rasmussen-Hirschman para a identificação de setores-chave, tem-se que o setor de fertilizantes pode ser classificado como um setor-chave da economia brasileira, tendo em vista que as forças de suas ligaçóes para frente estão acima da média. O contraste entre os índices de ligação para frente e para trás para o setor de fertilizantes já era esperado, dadas as características desse setor, que importa grande parte de seus principais insumos e realiza uma relativamente baixa agregação de valor em seu processo produtivo, mas que é fornecedor de um dos principais insumos para a agropecuária brasileira.

\section{CONCLUSÃO}

Este artigo buscou analisar o papel do setor de fertilizantes e suas inter-relações com os demais setores produtivos do país diante de mudanças no desempenho do setor. A partir dos resultados encontrados para os multiplicadores, pôde-se constatar que além de ser um setor essencial para o desenvolvimento econômico da agricultura nacional, esse se encontra entre as principais atividades quando se trata da capacidade de multiplicação de produção, emprego e renda em resposta às variaçóes na demanda agregada.

Especificamente para a produção, o resultado do multiplicador apontou que o setor ficou na vigésima posição, no ranking composto por 57 setores. Quanto aos multiplicadores de emprego e renda, as colocaçôes foram ainda melhores, com o setor assumindo a $6^{\underline{a}}$ e a $12^{\underline{a}}$ posição, respectivamente. $O$ setor de fertilizantes também pode ser considerado um setor-chave para a economia brasileira, pelo critério proposto por Rasmussen-Hirschman. Esse resultado indica o potencial do setor em contribuir para a dinâmica da economia brasileira por meio de suas ligaçóes de compra e, principalmente, de venda. 
Entăo, considerados os multiplicadores e os índices de ligação, têm-se evidências da importância do setor de fertilizantes para a economia brasileira, e do fato que seu desempenho exerce papel fundamental para o dinamismo e crescimento do país.

Os resultados apresentados permitem concluir que ações positivas relacionadas ao setor de fertilizantes, no sentido de reduzir sua dependência do mercado externo, podem favorecer o desempenho não apenas do setor, mas também de outras atividades que com ele se relacionam, direta ou indiretamente. Nesse escopo, destacam-se as atividades agrícolas, altamente dependentes dos fertilizantes para manterem, e mesmo, elevarem sua produtividade. Atualmente, essas atividades são expostas a riscos advindos do mercado externo, cujas oscilaçôes têm impactos relevantes sobre os custos de produção das principais culturas do país.

Ressalta-se que estudos disponíveis na literatura destacam que investimentos no setor de fertilizantes têm sido limitados devido à baixa disponibilidade de matérias-primas, além de questóes logísticas, tributárias e ambientais, que fogem do escopo de análise deste artigo (Cruz, Pereira e Figueiredo, 2017). Tal fato indica também que podem ser necessárias mais pesquisas ligadas ao desenvolvimento de novas tecnologias de fertilizantes e à identificaçáo de fontes alternativas de nutrientes, de modo a diminuir a dependência atual em relação às importaçóes e trazer mais segurança à cadeia produtiva do agronegócio.

Este trabalho, ao analisar de forma isolada o setor de fertilizantes, utilizando a matriz insumo-produto e o cálculo de multiplicadores de impacto sobre renda, produto e emprego, contribui com informaçóes que podem subsidiar a tomada de decisão de agentes públicos e privados.

\section{REFERÊNCIAS}

AMORIM, A. L.; CORONEL, D. A.; TEIXEIRA, E. C. A agropecuária na economia brasileira: uma análise de insumo-produto. Perspectiva Econômica, v. 5, n. 2, p. 1-19, 2009.

ANDA - ASSOCIAÇÃO NACIONAL PARA DIFUSÁO DE ADUBOS. Principais indicadores do setor de fertilizantes. São Paulo: ANDA, 2018. Disponível em <http://anda.org.br/estatisticas/>. Acesso em: 11 fev. 2019.

BENITES, V. M.; POLIDORO, J. C.; RESENDE, A. V. Oportunidades para a inovação tecnológica no setor de fertilizantes no Brasil. Boletim Informativo da SBCS, 2010. Disponível em: <https://bit.ly/319PAeF>. Acesso em: 4 jul. 2017.

BNDES - BANCO NACIONAL DO DESENSOVLMENTO. Panorama atual e perspectivas de desenvolvimento do setor de fertilizantes no Brasil. Brasília: BNDES, 2010. Disponível em: <https://bit.ly/2Je0YJG>. Acesso em: 13 mar. 2017. 
BRADSHER, K.; MARTIN, A. World's poor pay price as crop research is cut. The New York Times. 2008. Disponível em: <https://nyti.ms/2HIoOwk>. Acesso em: 15 jul. 2017.

BRASIL. Ministério da Agricultura, Pecuária e Abastecimento. Balança comercial brasileira e balança comercial do agronegócio: 1997 a 2016. Brasília: Mapa, 2017. Disponível em: <https://bit.ly/3nXvk1C>. Acesso em: 24 jul. 2017.

Ministério do Trabalho e Emprego. Relaçáo anual de informações sociais. Brasília: tem, 2009. Disponível em: <https://bit.ly/39ioxM5>. Acesso em: 24 jul. 2017.

CARDOSO, C. E. L.; GUILHOTO, J. J. M. Impactos da substituiçáo de importaçóes de produtos agrícolas e agroindustriais na economia brasileira. Cruz das Almas: Ufba, 2003.

CASIMIRO-FILHO, F. Contribuiçóes do turismo à economia brasileira. 2002. 220f. Tese (Doutorado) - Universidade de São Paulo, Piracicaba, São Paulo, 2002.

CEPEA - CENTRO DE ESTUDOS AVANÇADOS EM ECONOMIA APLICADA. Produto Interno Bruto do agronegócio brasileiro. Piracicaba: Cepea, 2017. Disponível em: <https://bit.ly/33nBhNQ>. Acesso em: 12 out. 2017.

CONAB - COMPANHIA NACIONAL DO ABASTECIMENTO. Acompanhamento da safra brasileira - Gráos: décimo segundo levantamento. Brasília: Conab, 2016. Disponível em: <https://bit.ly/3q6Jobc>. Acesso em: 28 out. 2017.

COSTA, M. M.; SILVA, M. O. A indústria química e o setor de fertilizantes. In: SOUZA, F. L. (Ed.). BNDES 60 anos: perspectivas setoriais. v. 2. Rio de Janeiro: BNDES, 2012.

CRUZ, A. C.; PEREIRA, F. S; FIGUEIREDO, V. S. Fertilizantes organominerais de resíduos do agronegócio: avaliação do potencial econômico brasileiro. BNDES Setorial, n. 45, p. 137-187, 2017.

FAO - FOOD AND AGRICULTURE ORGANIZATION OF THE UNITED NATIONS. Fertilizer use by crop in Brazil. Roma: FAO, 2004. Disponível em: <https://bit.ly/3m9TFkq>. Acesso em: 25 fev. 2019.

. Food Outlook. Roma: FAO, 2018. Disponível em: <https://bit.ly/ 2JeLXHA>. Acesso em: 20 out. 2019.

FGV - FUNDAÇÃO GETÚLIO VARGAS. Índices de preços ao atacado. Portal IBRE, 2017. Disponível em <https://bit.ly/3qfhkmb>. Acesso em: 22 nov. 2017.

FIGUEIREDO, M. G. et al. Matriz insumo-produto de Mato Grosso 2007: construção e análise dos principais indicadores econômicos. Revista de Estudos Sociais, v. 13, n. 26, 2011. 
FIGUEIREDO, M. G.; BARROS, A. L. M.; GUILHOTO, J. J. M. Relação econômica dos setores agrícolas do Estado do Mato Grosso com os demais setores pertencentes tanto ao Estado quanto ao restante do Brasil. Revista de Economia e Sociologia Rural, Brasília, v. 43, n. 3, p. 557-575, 2005.

GASQUES, J. G.; BACCHI, M. R. P; BASTOS, E. T. Crescimento e Produtividade da Agricultura Brasileira de 1975 a 2016. Carta de Conjuntura, n. 38, 2018. Disponível em: <https://bit.ly/37h5EX1>. Acesso em: 5 fev. 2019.

GILIO, L.; CASTRO, N.R. O crescimento do agronegócio realmente tem se refletido em maior renda para os agentes do setor? Piracicaba: Cepea; Esalq/ Usp, 2018. Disponível em: <https://bit.ly/39mas07>. Acesso em: 27 fev. 2019.

GUILHOTO, J. J. M. et al. Índices De Ligações e Setores Chave na Economia Brasileira: 1959-1980. Pesquisa e Planejamento Econômico, v. 24, n. 2, p. 287-314, 1994.

Análise de insumo-produto: teoria, fundamentos e aplicaçôes. São Paulo: FEA-USP, 2009.

GUILHOTO, J. J. M.; SESSO FILHO, U. A. Estimação da matriz insumo-produto utilizando dados preliminares das contas nacionais: aplicação e análise de indicadores econômicos para o Brasil em 2005. Economia e Tecnologia, v. 23, out./dez. 2010.

HIRSCHMAN, A. O. The strategy of economic development. New Haven: Yale University Press, 1958.

IBGE - INSTITUTO BRASILEIRO DE GEOGRAFIA E ESTATÍSTICA. Produçáo Industrial Anual (PIA). Rio de Janeiro: IBGE, 2009a. Disponível em: <https://bit.ly/2JlTCDu>. Acesso em: 03 abr. 2017.

Pesquisa Nacional por Amostra de Domicílios (PNAD). Rio de Janeiro: IBGE, 2009b. Disponível em: <https://bit.ly/3o2MbQR>. Acesso em: 03 abr. 2017.

Sistema de contas nacionais. Rio de Janeiro: IBGE, 2010. Disponível em: <https://bit.ly/3fFK8iN>. Acesso em 03 abr. de 2017.

IFA - ASSOCIAÇÃO INTERNACIONAL DA INDÚSTRIA DE FERTILIZANTES. Fertilizer Outlook. Amsterdam: IFA, 2016. Disponível em: <://www. ifastat.org/>. Acesso em: 25 abr. 2017.

LOPES, A. S.; GUILHERME, L. R. G. Fertilidade do solo e produtividade agrícola. In: NOVAIS, R. F. et al. (Ed.). Fertilidade do solo. Viçosa: Sociedade Brasileira de Ciência do Solo, 2007.

MCGILVRAY, J. Linkages, key sectors and develolpment strategy. In: LEONTIEF, W. (Ed.). Structure, system and economic policy. Cambridge: Cambridge University Press, 1977. 
MILLER, R. E.; BLAIR, P. D. Input-output analysis: foundations and extensions. Cambridge: Cambridge University Press, 2009. 750 p.

NOGUEIRA, A. C. L. Agricultura: o mercado de fertilizantes no Brasil. São Paulo: Fipe, maio 2008.

PEREIRA, M. Z.; BASTOS, S. Q. A.; PEROBELLI, F. S. Análise Sistêmica do setor de serviços no Brasil para o ano de 2005. Pesquisa e Planejamento Econômico. v. 43, n. 1, 2013.

PROCHNOW, L. I. Desenvolvimento da agricultura e da produçáo de fertilizantes no Brasil. Goiânia: Brasil Agro, 2018. Disponível em <https://bit. ly/36aUUdF> Acesso em: 25 fev. 2019.

RASMUSSEN, P. N. Studies in inter-sectoral relations. Amsterdam: North Holland. 1956.

SAAB, A. A.; PAULA, R. A. O mercado de fertilizantes no Brasil - Diagnósticos e propostas de políticas. Revista de Política Agrícola, v. 25, n. 2, 2008.

SABOIA, J.; KUBRUSLY, L. Diferenças regionais e setoriais na indústria brasileira. Economia Aplicada. v. 12, n. 1, 2008.

SANTOS, V. E. et al. Análise do setor de produção e processamento de café em Minas Gerais: uma abordagem matriz insumo-produto. Revista de Economia e Sociologia Rural - RESR. v. 47, n. 2, 2009.

SEAE - SECRETARIA DE ACOMPANHAMENTO ECONÔMICO. Panorama do mercado de fertilizantes. Brasília: Seae, 2011. Disponível em: <https://bit. ly/2VbWh5C> Acesso em: 4 abr. 2017.

SOUZA, E. C. et al. Impactos da produção e do abate e processamento de frangos de corte na economia paranaense. Planejamento e Políticas Públicas, n. 38, 2012. UFMT - UNIVERSIDADE FEDERAL DO MATO GROSSO. Manual de instruçóes para uso do banco de dados da matriz insumo-produto inter-regional Mato Grosso e resto do Brasil. Cuiabá: UFMT, 2007. Disponível em: <https:// bit.ly/2KDKta2>. Acesso em: 3 fev. 2019.

Data da submissão: $31 / 7 / 2017$

Primeira decisão editorial em: 4/10/2018

Última versão recebida em: 8/3/2019

Aprovação final em: 8/3/2019 
